\title{
Producción de biogás en escuelas rurales
}

Griselda Medina ${ }^{1}$, Virginia Monzón ${ }^{2}$, Sogari Noemî́, Cecilia Mena, Ricciardi Eduardo $\left({ }^{*}\right)$

\section{RESUMEN:}

Se expone en el presente trabajo el desarrollo de un proyecto de extensión, en el cual se fomenta un sistema de difusión, capacitación y asistencia dirigido a alumnos y docentes de distintos niveles educativos pertenecientes a zonas rurales. Investigadores y alumnos de G.I.E.S.M.A de la Fa.Ce. $\mathrm{Na}$ de la UNNE, promueven el uso de energía renovable mediante la construcción de un biodigestor, que permite la degradación de efluentes de corrales y tambos para la producción de biogás. La metodología de enseñanza aplicada impulsa el trabajo interdisciplinar entres distintas asignaturas, con el propósito de fortalecer el proceso de enseñanza y fomentar el aprendizaje significativo y colaborativo a partir de la construcción de una tecnología alternativa simple y económica.

Palabras claves: educación, biogás, integración, aprendizaje.

\section{INTRODUCCIÓN:}

Si bien la sociedad está condicionada por variables socioeconómicas, puede promover el cambio social a través de la formación de personas críticas, comprometidas y capaces de transformar la realidad (Alcalá; 2002).

Optimizar la calidad educativa en la actualidad, requiere de nuevos esquemas de enseñanza que proporcionen un contexto que involucren el trabajo cooperativo entre diversas disciplinas, de tal manera de lograr desarrollar un aprendizaje efectivo, práctico, integrado y significativo, desde el deseo del saber, de manera de lograr despertar el interés y la predisposición hacia el aprendizaje por parte del educando.

Las estrategias metodologías seleccionadas admiten el intercambio de ideas entre pares e involucran actividades que promueven un aprendizaje autónomo y colaborativo, donde desarrollan capacidades para la

(*)Facultad de Ciencias Exactas y Naturales y Agrimensura. UNNE. Corrientes. Avenida Libertad 5460. Código Postal 3400. Tel. 0379 - 4473931

${ }^{1}$ Pasante no rentada en el PI17F015 Resol No 030618 CD Fa.Ce.Na.

${ }^{2}$ Becaria EVC Fa.Ce.Na UNNE 2018.

${ }^{3}$ Directora del proyecto financiado por SGCYT de la UNNE PI17F015. 
investigación y actitudes científicas, para el cual adoptan una postura crítica y fundamentada de los diferentes temas relacionados con la ciencia.

La ciencia no solo transmite conocimientos relacionados con física, química, biología y matemática, sino que intenta además promover actitudes prácticas que sitúan a los alumnos en un lugar de mayor participación y compromiso, que convergen en la apropiación de nuevos saberes y habilidades.

El uso apropiado de materiales de bajo costo permite la construcción de una tecnología alternativa simple, que involucra la generación de biogás a partir de la degradación de efluentes de corrales y tambos, con el cual se intenta difundir el uso de energías renovables, fomentar el cuidado del medio ambiente y el trabajo interdisciplinar entre diversas áreas tales como: física, química, matemática y biología.

La actividad experimental cumple un papel importante dentro del proceso enseñanza-aprendizaje, si se dirige de manera consciente e intencionada a lograr que las ideas previas de los estudiantes evolucionen a conceptos más elaborados y cercanos a los científicos (Tamayo y Sanmartí, 2007; Tamayo, 2009).

Entonces, la generación de biogás, facilita la construcción funcional y significativa de nuevos conocimientos, permitiendo de esta manera la apropiación de conceptos básicos sobre energía renovable y otros temas relacionado, se logra construir un proyecto de trabajo de forma conjunta y organizada, con el objetivo de mejorar el proceso de enseñanza-aprendizaje, despertar el interés, promover un mayor nivel de dialogo y debate colectivo, estimular la reflexión y el compromiso hacia el cuidado del medio ambiente, cuya intencionalidad es educar joven críticos, reflexivos e involucrados en su formación.

\section{MÉTODOS Y MATERIALES:}

La difusión de esta propuesta de trabajo fue destinada a alumnos y docentes de distintos niveles educativos de zonas rurales, cuya presentación teoría abarca conceptos tales como: contaminación, energía, energía renovable, tipos de energía renovable, biodigestor, degradación de la materia, biogás, y cuidado del medio ambiente.

La recuperación de los saberes previos del educando es primordial, para conducir la enseñanza a partir de sus ideas o reflexiones, creando un ambiente dinámico e interactivo, de tal manera de construir un saber que resulte ser para el alumno un aprendizaje uniforme, verdadero y significativo. Es importante abordar cada clase a partir preguntas dirigidas hacia el nuevo contenido a desarrollar, con el objetivo de propiciar la participación activa y la recuperación de los conocimientos previos del grupo clase.

La presentación de un biodigestor construido con materiales reutilizables y de bajo costo, permite enriquecer aún más el aprendizaje del educando. Por medio de una sencilla técnica operatoria se le enseña al alumno cómo debe realizarse el armado del sistema, que posteriormente deberán construir, para luego poder monitorear de forma continua el funcionamiento del mismo. 


\section{Construcción del biodigestor:}

- Materiales: 2 baldes de 20 litros, llaves de paso de gas, 1 balde de 10 litros, canillas de PVC, tubos de PVC, pegamento, cortantes, mangueras plásticas, mechero bunsen.

El biodigestor, es un contenedor her- mético que permite la descomposición de la materia orgánica para la obtención de biogás, bajo condiciones anaeróbicas. El sistema consta de diferentes partes; un biodigestor y un gasómetro elaborados mediante baldes de plástico (baldes o tachos de pinturas), conectados entre sí.

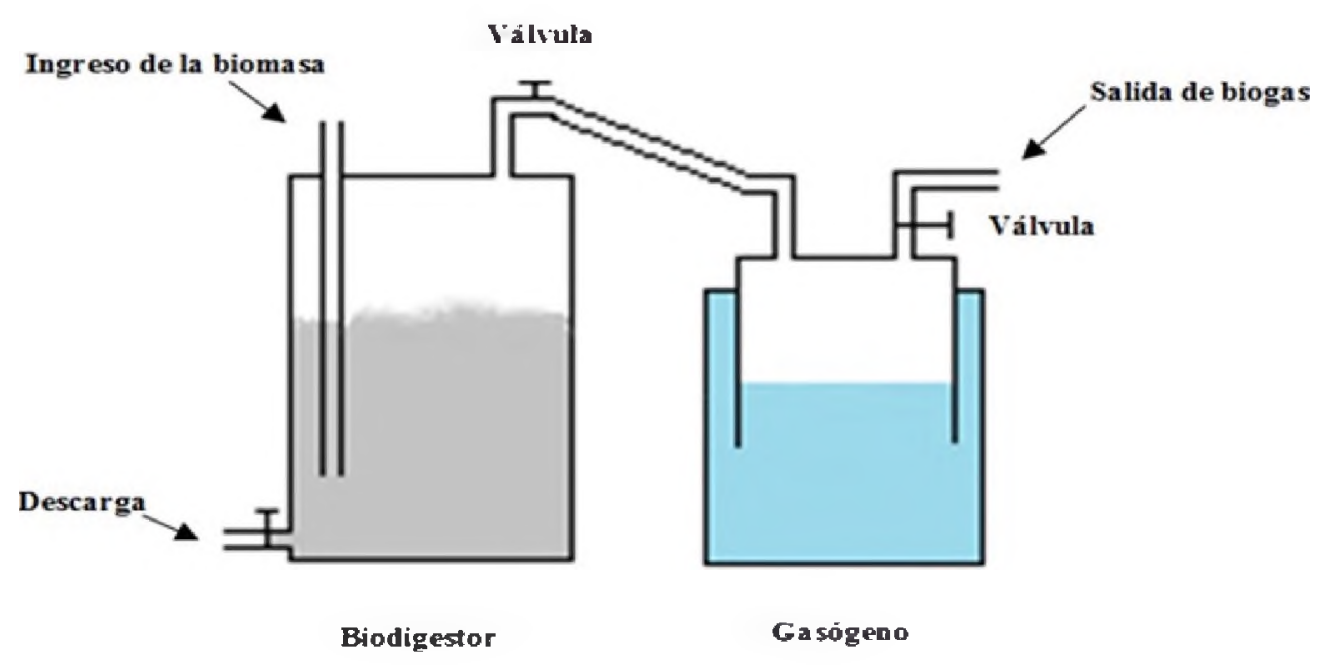

Fig3: esquema ilustrativo del reactor-gasógeno

El primero con tapa hermética y dos entradas con tubos de PVC, una para el ingreso de la materia orgánica, y la otra para la salida del gas, en la parte inferior del balde existe una salida con una canilla de PVC para descarga de desechos.

El segundo se elaboró mediante, a modo de campana utilizando dos baldes superpuestos con agua en su interior, con dos orificios (entrada y salida del gas) con llaves de paso y manguera de plástico por medio del cual se conectó al biodigestor.

Una vez culminado la construcción de ambos dispositivos, se agregó una cierta cantidad de materia orgánica acuosa (es- tiércol vacuno más agua) al biodigestor por uno de los orificios presente en la tapa, se dejó reposar por varios días a una temperatura adecuada para lograr una mejorar producción de gas metano.

En el gasómetro se recolectó el gas (metano) generado por el reactor. Se pudo percibir la producción de gas debido a que uno de los baldes que forma parte del gasómetro (campana) se impulsa hacia arriba tras aumentar el volumen de gas, este incremento pudo ser detectado mediante una escala graduada ubicada en el exterior de la campana.

Los alumnos acompañados con el per- 
sonal docente van realizando lecturas de cómo evoluciona el nivel de campana, utilizando la regla graduada en centímetros que permite medir el nivel del agua que está siendo desalojada y se va detectando la presencia o ausencia de metano utilizando un

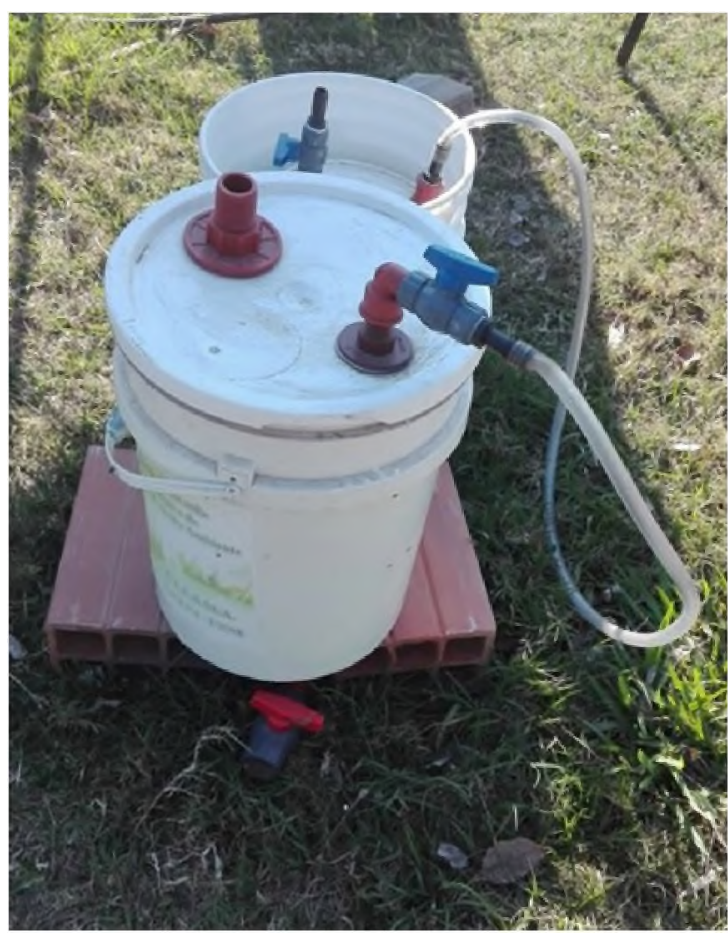

Fig. 4: Sistema: biodigestor-gasómetro

\section{RESULTADOS Y DISCUSIÓN:}

Se logró construir de esta manera un dispositivo práctico y sencillo a partir de materiales reutilizables, de fácil acceso y económico para confeccionarlo en escuelas u hogares rurales, que favorece el desarrollo y aprendizaje de las energías sustentables, como otros conceptos relacionados con física, química, biología y matemática, como ser volumen, principio de Arquímedes, diferencia de densidades entre un gas y un lí- mechero de bunsen conectado a la salida de gas que posee el gasógeno (fig. 3).

Las siguientes imágenes visualizan como quedó armado el biodigestor con materiales simples de conseguir y de bajo costo.

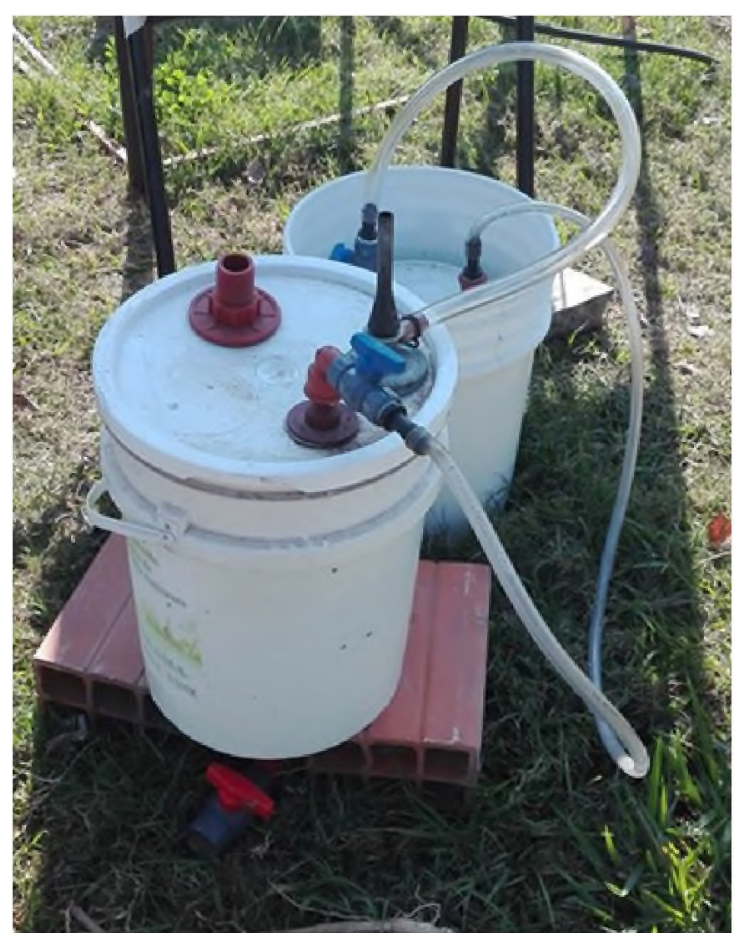

Fig. 5: Comprobación de presencia de metano

quido, presión, materia orgánica, bacterias, influencia de la temperatura en el proceso de degradación, etc., que permitirá a los alumnos comprender los diversos temas a partir de la propia experimentación, además desarrollar destrezas colaborativas entre alumnos y docentes de las diferentes áreas involucradas, con el propósito de enriquecer aún más el aprendizaje de estudiantes y crear conciencia sobre el cuidado sobre el medio ambiente. 


\section{CONCLUSIÓN:}

La construcción del biodigestor para la generación de biogás, bajo condiciones anaeróbicas, permite un aprendizaje constructivo y significativo que posibilita la integración de distintos saberes, estimula el pensamiento, crea conciencia sobre el cuidado del medio ambiente, y mejora la calidad educativa desde la práctica de la enseñanza, logrando de esta manera formar sujetos activos, reflexivos e involucrados en su formación a partir de un aprendizaje efectivo, práctico e integrado.

\section{ABSTRACT:}

This paper presents the development of an extension project, which promotes a system of dissemination, training and assistance for students and teachers of different educational levels in rural areas. The joint work of researchers and students of G.I.E.S.M.A of the Fa.Ce.Na of the UNNE, promote the use of renewable energy through the construction of a biodigester, which allows the degradation of effuents from pens and dairy farms for the production of biogas. The applied teaching methodology promotes interdisciplinary work between different subjects, with the purpose of strengthening the teaching pro- cess and encouraging meaningful and collaborative learning based on the construction of a simple and economical alternative technology.

KEYWORDS: education, biogas, integration, learning.

\section{REFERENCIAS}

- Alcalá, María t. (2002). El conocimiento del profesor y enfoques didácticos.

- Gropelli, Eduardo s. y Giampaoli Orlando a. (2001). El camino de la biodigestión. Ambiente y tecnología socialmente apropiada. 2001.

- Sogari N. (2012) Análisis de las propiedades físico químicas del biogás obtenido de la degradación anaeróbica de residuos orgánicos. AVERMA. Vol. 16. ISSN: 0329-5184.

- Tamayo A., Ó.E. (2009). Didáctica de las ciencias: La evolución conceptual en la enseñanza y el aprendizaje de las ciencias. Manizales: Editorial Universidad de Caldas.

- Tamayo A., Ó.E. y Sanmartí, N. (2007). “High-School Students' Conceptual Evolution of the Respiration Concept from the Perspective of Giere's Cognitive Science Model". International Journal of Science Education, No. 2, Vol. 29, pp. 215-248 